\title{
Correspondence
}

\section{Informed dissent}

SIR

To continue my prolonged debate with Madeleine Simms on informed dissent, may we assume from her letter in the December 1986 issue that, in defence of a particular, unspecified quality of life, it is legitimate to kill anyone who stands in our way? Or are the parents of handicapped children the only ones who should be accorded this 'right'.

Surely there are other groups whose life-style is threatened by the need or duty to care for someone else, and if we were to allow killing to solve every such problem, we would probably all be potential victims. This is a particularly dangerous and greasy slippery slope, I think.

In order to be consistent and ethically sound, we would have to decide just how threatening a person must be to a specified life-style before, in the absence of alternatives or mitigating factors, we may justify killing. The right of an individual not to be killed would then depend not on any intrinsic or conferred right to life, but potentially upon the most trivial of external factors.

For instance, I* am confined to a wheelchair and unable to stand. If I am in a building with an inaccessible bathroom, how many times have I a 'right' to expect others to carry me there before I become an intolerable burden to them, and therefore a suitable candidate for death? Are architects then to be the final arbiters of life and death for those like me?

If the answer to inadequate facilities for the handicapped is to kill them, then we must presumably also kill those currently suffering in inadequate institutions, as well as immediately dispatching victims of illness or accident. We then, ipso facto, remove any real need for institutions, but we also remove all semblance of a 'welfare state'. The weak, vulnerable and ill would then be entitled to a quick and possibly painless death, not to treatment or rehabilitation.

There are, I think, two ways to approach the nightmare world Ms Simms paints of overburdened carers and handicapped children 'languishing in institutions'. The first is to accept that this sad state of affairs cannot or will not be changed, and thereby to justify. killing anyone who is 'burdensome' to someone else.

The second is to acknowledge that we are all in fact interdependent and all rely on others in certain circumstances. I believe Ms Simms is right in saying that mothers should insist that society starting with the medical profession should be made aware of the problems they face, and be required to function in the 'real world' of practical solutions. But if we are to retain our legal and social framework, designed to protect the weakest and most vulnerable, we need to avoid both professional 'tunnel vision' and the injustice of killing the weakest to protect the strongest. In doing this, the right to life, rather than the quality of life, must take precedence.

We need then to decide on a solution which will be durable, consistent and applicable in all situations. If all those perceived as burdensome may be killed, and such decisions are supported by government policies, then we begin to approach very closely the Nazi solution of Hadamar hospital, where those designated 'economic lumber' were eliminated 'for the public good'.

If only some of them may be killed, who will decide which - parents? doctors? architects? politicians? If we chose this course, irrelevant factors such as access, aesthetic preference and interpretation of individual or collective responsibility would have to play a part in determining who was to live or die.

On the other hand, if we decide neither of these approaches is acceptable, and none may be killed, we must all ultimately share the duty to care. This is already done in the case of healthy children whose parents cannot or will not cope with them. If adoption cannot be arranged, the State assumes collective responsibility for them, and they are cared for at our expense. The same should also be true for handicapped children though, as with the healthy, we should first take all possible steps to enable the parents to keep them, if at all possible. Ultimately though for any child we need to acknowledge that while the 'quality of life' may be poorer if we assume the collective responsibility of institutional care, the right to life takes precedence over any such subjective considerations.

Claiming that our desirable quality of life can be achieved only by sentencing others to death is to live in a false, blindfolded bliss of violently acquired and desperately fragile happiness. This may be Madeleine Simms's idea of a 'life worth living'. It is not mine.

\section{ALISON DAVIS Rosemary, 6 Green Lane, Parsons Heath, Colchester, Essex}

\section{Informed dissent: a further response}

SIR

In a moral climate where an increasing number of people seem to be adopting an uncaring attitude towards those less fortunate than themselves, it is always heartening to hear the likes of Madeleine Simms attempting to further the interests of those who are currently forced to look after handicapped relatives ('Informed dissent', JME Dec 1986). However, several serious errors in her argument need to be corrected if we are not to fall into a moral confusion which at best is wasteful of resources, 